\title{
Leucocyte Count Does Not Improve the Diagnostic Performance of a Diagnostic Score (DS) in Distinguishing Acute Appendicitis (AA) from Nonspecific Abdominal Pain (NSAP)
}

\author{
JANNICA MEKLIN $^{1 *}$, MAARET ESKELINEN $^{1 *}$, KARI SYRJANEN $^{2,3}$ and MATTI ESKELINEN ${ }^{1}$ \\ ${ }^{1}$ Department of Surgery, Kuopio University Hospital and School of Medicine, \\ University of Eastern Finland, Kuopio, Finland; \\ ${ }^{2}$ Molecular Oncology Research Center, Barretos Cancer Hospital, Barretos, Brazil; \\ ${ }^{3}$ SMW Consultants, Ltd., Kaarina, Finland
}

\begin{abstract}
Background/Aim: Although, acute appendicitis (AA) and nonspecific abdominal pain (NSAP) are the most common diagnoses among secondary care patients with acute abdominal pain, the diagnostic performance of leucocyte count (LC) in DS (Diagnostic Score) model is rarely considered. Patients and Methods: As an extension of the World Organisation of Gastro-Enterology Research Committee (OMGE) acute abdominal pain study, 1,333 patients presenting with acute abdominal pain were included in the study. The clinical history and diagnostic symptoms $(n=22)$, signs $(n=14)$ and tests $(n=3)$ in each patient were recorded in detail, and the collected data were related with the final diagnoses of the patients. Results: In the ROC comparison test, there was no statistically significant difference in the performance of $D S_{L C-}(D S$ without $L C)$ and $D S_{L C+}(D S$ with $L C)$. The highest sensitivities of the $D S_{L C-}$ and $D S_{L C+}$ tests for detecting AA were $86 \%$ (95\%CI=81$90 \%)$ and $87 \%(95 \% C I=82-91 \%)$, respectively. The highest specificities of the $D S_{L C-}$ and $D S_{L C+}$ tests for detecting $A A$ were 98\% (95\%CI=97-99\%) and 98\% (95\%CI=96-99\%), respectively. Conclusion: DS could assist the clinician in differentiating AA from NSAP and other causes of acute abdominal pain. Importantly, LC does not improve the diagnostic performance of a $D S$ in $A A$.
\end{abstract}

This article is freely accessible online.

*These Authors contributed equally to this study.

Correspondence to: Matti Eskelinen, MD, Ph.D., School of Medicine, University of Eastern Finland, P.O. Box 100, FI-70029 KYS, Finland. Tel: +358 17173311, Fax: +358 17172611, GSM: +358 400969444, e-mail: matti.eskelinen@kuh.fi

Key Words: Acute appendicitis, non-specific abdominal pain, diagnostic score, leucocyte count, ROC, HSROC.
We have studied acute abdominal pain in connection with the survey on acute abdominal pain by the Research Committee of the World Organization of Gastroenterology (OMGE) (1) and investigated the diagnostic performance of history-taking and clinical examination in acute appendicitis (AA) (2), nonspecific abdominal pain (NSAP) (3), acute small bowel obstruction (4) and acute renal colic (5). Given that AA and NSAP are the most common diagnoses among secondary care patients with acute abdominal pain, the diagnostic performance of history-taking, clinical examination and possible diagnostic score (DS) is extremely important. However, the differential diagnosis of AA and NSAP is not always easy due to many similarities in the clinical presentation at the onset and many cases may be misdiagnosed in the initial diagnostic setting. Although, there is some DS models available $(2,6-10)$ in the diagnosis of acute abdominal pain (AAP) there is continuing debate on the shortcomings of the DS models and we thus aimed to examine the performance of our DS model i) without leucocyte count $\left(\mathrm{DS}_{\mathrm{LC}-}\right)$ and ii) with leucocyte count $\left(\mathrm{DS}_{\mathrm{LC}+}\right)$.

\section{Patients and Methods}

Criteria for inclusion in this study and the diagnostic criteria were those set out by the OMGE Committee (1). There were 636 males $(47.7 \%)$ and 697 females $(52.3 \%)$ with a mean age $( \pm \mathrm{SD})$ of $38.0 \pm 22.1$ years (Table I).

The clinical findings in each patient were recorded in detail (Tables II and III), using a predefined structured data collection sheet. The disease history was recorded and categorised as shown in Tables II and III. The examination of the clinical symptoms, signs and tests were conducted using a standard technique and the results were graded positive or negative (Tables II and III). The diagnosis of acute abdominal pain (AAP) was done by considering all symptoms, signs and results of the laboratory tests together and the diagnostic criteria of AA defined elsewhere (1-3).

The likelihood ratio of a positive test result $(\mathrm{LR}+)$ shows how many times greater the probability of a positive test result is among 
Table I. The distribution of diagnoses in patients with acute abdominal pain according to initial decision.

\begin{tabular}{lcr}
\hline Disease category & No. of patients & $\%$ \\
\hline Non-specific & & \\
Abdominal pain (1)* & 552 & 41.4 \\
Acute appendicitis (2) & 402 & 30.2 \\
Acute cholecystitis (3) & 135 & 10.1 \\
Small bowel obstruction (4) & 57 & 4.3 \\
Dyspepsia (5) & 27 & 2.0 \\
Renal colic (6) & 59 & 4.4 \\
Diverticular disease (7) & 13 & 1.0 \\
Mesenteric lymphadenitis (8) & 9 & 0.7 \\
Acute pancreatitis (9) & 29 & 2.2 \\
Perf. peptic ulcer (10) & 6 & 0.5 \\
Urinary tract infection (11) & 10 & 0.8 \\
Acute gynae. disease (12) & 12 & 0.9 \\
Miscellaneous (13) & 22 & 1.7 \\
\hline Total & 1333 & 100.0 \\
\hline
\end{tabular}

*OMGE Rank order number in parenthesis.

patients with acute appendicitis (AA) than in subjects without acute appendicitis. LR+ should always be higher than 1.0 and LR+ of a good test (diagnostic method) is 10 or higher. The likelihood ratio of a negative test result (LR-) is the probability of a negative test result among patients with AA divided by the corresponding probability among the subjects without acute AA. LR- should be less than 1 and the LR-ratio of a good test is less than 0.1 .

Statistical analysis. In the computation of the diagnostic score (DS), a logistic stepwise multivariate regression analysis of the SPSS Statistics 26.0.0.1 (IBM, NY, USA) was used. All the variables presented in Tables II and III were included in the analysis as binary data $e . g$. AA (1) and NSAP (0). The multivariate analysis was used to disclose the variables with an independent predictive value. Using the coefficients of the regression model, a DS was built and its predictive value for AA was studied. The coefficient of the multivariate analysis shows the relative risk $\left(R R=e_{-}, n=\beta\right)$ of a patient with a given symptom or sign to have an AA.

The rest of the analyses were performed with STATA/SE version 16.1 (StataCorp, College Station, TX, USA). Statistical tests presented were two-sided, and $p$-value $<0.05$ was considered statistically significant. Using $2 \times 2$ tables, we calculated sensitivity (Se) and specificity (Sp) with $95 \%$ confidence intervals (95\% CI) for each symptom, sign or test, and created separate forest plots for showing each set of data, separately for each diagnostic variable. We calculated the summary estimates of Se and Sp, positive (LR+) and negative likelihood ratio (LR-) and diagnostic odds ratio (DOR), using a random effect bivariate model and fitted the summary hierarchical receiving operating characteristic (HSROC) curves including all diagnostic variables in the $\mathrm{DS}_{\mathrm{LC}-}$ and $\mathrm{DS}_{\mathrm{LC}+}$ models, using the AA endpoint.

Using the STATA's predict tool, we also made posterior predictions [Empirical Bayes (EB) estimates] of the Se and $\mathrm{Sp}$ in each variable in $\mathrm{DS}_{\mathrm{LC}-}$ and $\mathrm{DS}_{\mathrm{LC}+}$. Analogous to its use in metaanalysis, EB estimates here give the best estimates of the true $\mathrm{Se}$ and $\mathrm{Sp}$ for each diagnostic variable, the variable-specific point estimates usually shrinking toward the summary point of the HSROC. We explored the statistical heterogeneity between diagnostic variables (Tables II and III) and DS models (Tables II and III) through visual examination of the forest plots and the HSROC curves. To study the potential bias, we used the Cook's distance to check for the particularly influential variables, together with a scatter plot of the standardised (level 2) residuals to check for the variables that are distinct outliers.

\section{Results}

Diagnostic performance of the symptoms. The pooled overall $\mathrm{Se}$ and $\mathrm{Sp}$ of the diagnostic symptoms for detecting AA were $75 \% \quad(95 \% \mathrm{CI}=60-87 \%)$ and $35 \% \quad(95 \% \mathrm{CI}=23-49 \%)$, respectively (Figures 1 and 2). In 13 diagnostic symptoms the Se was higher than $75 \%$, and the $\mathrm{Sp}$ was higher than $35 \%$ in 10 diagnostic symptoms. The five best diagnostic symptoms (vertigo, jaundice, micturition, drugs for abdominal pain and use of alcohol) showed $97-100 \%$ Se in the diagnosis of AA (Figure 1). The four best diagnostic symptoms showed $69-91 \% \mathrm{Sp}$, the initial pain being the most specific $(91 \%)$ followed by the intensity of the abdominal pain, sex and location of the pain at diagnosis (Figure 2).

Diagnostic performance of the signs and tests. The pooled overall Se and Sp of the clinical signs and tests for detecting AA were $87 \%(95 \% \mathrm{CI}=81-92 \%)$ and $38 \%(95 \% \mathrm{CI}=19-59 \%)$, respectively (Figures 3 and 4). For 10 clinical signs and tests, the Se exceeded $87 \%$, and the Sp was higher than $38 \%$ for 10 diagnostic signs. The best four clinical signs and tests (mass, urine, distension and Murphy's sign positive) showed 96-100\% Se for AA (Figure 3). The best four clinical signs and tests showed $71-98 \% \mathrm{Sp}$, rigidity $(98 \%)$ being the most specific, followed by rectal digital tenderness, leucocyte count (LC) and rebound (Figure 4).

Diagnostic performance of the DS without leucocytes $\left(D S_{L C}\right)$. The most significant predictors were used to construct six different $\mathrm{DS}_{\mathrm{LC}-}$ formulas for AA diagnosis (Table IV). The pooled overall $\mathrm{Se}$ and $\mathrm{Sp}$ of these six $\mathrm{DS}_{\mathrm{LC}-}$ models for $\mathrm{AA}$ diagnosis were $77 \%(95 \% \mathrm{CI}=70-84 \%)$ and $95 \%(95 \% \mathrm{CI}=93-$ 97\%) (Figures 5 and 6). At the best diagnostic performance level for AA, the $\mathrm{DS}_{\mathrm{LC}-}$ (formula DS I, Figures 5 and 6) showed $\mathrm{Se}$ of $82 \%(95 \% \mathrm{CI}=77-86 \%)$ and $\mathrm{Sp}$ of $95 \%$ $(95 \% \mathrm{CI}=93-97 \%)$. The formula without LC, showing the highest diagnostic performance for AA in HSROC analysis is as follows: $\mathrm{DS}_{\mathrm{LC}-}=-1.72 \times$ guarding (positive endpoint $=1$, negative endpoint $=0$ ) $-0.56 \times$ type of pain (positive endpoint $=1$, negative endpoint $=0$ ) $-0.9 \times$ pain at diagnosis (positive endpoint $=1$, negative endpoint $=0$ ) $-1.36 \times$ tenderness (positive endpoint $=1$, negative endpoint $=0$ ) $-3.32 \times$ rigidity (positive endpoint $=1$, negative endpoint $=0$ ) $-1.1 \times$ vomiting (positive endpoint $=1$, negative endpoint $=0$ ) $-1.44 \times$ previous abdominal 
Meklin et al: Performance of a Diagnostic Score in Acute Appendicitis

Table II. The clinical history of the patients with acute appendicitis versus non-specific abdominal pain.

\begin{tabular}{|c|c|c|c|c|c|c|}
\hline Clinical history variable & Positive endpoint & Negative endpoint & $\mathrm{TP}$ & FN & FP & $\mathrm{TN}$ \\
\hline 1. Gender & Male & Female & 149 & 268 & 121 & 346 \\
\hline $\begin{array}{l}\text { 2. Location of initial } \\
\text { pain (OMGE) }\end{array}$ & $\begin{array}{l}\text { Upper left or right quadrants } \\
\text { of abdomen }\end{array}$ & $\begin{array}{l}\text { Other quadrants } \\
\text { of abdomen }\end{array}$ & 6 & 264 & 57 & 557 \\
\hline $\begin{array}{l}\text { 3. Location of pain } \\
\text { at diagnosis (OMGE) }\end{array}$ & $\begin{array}{c}\text { Right lower quadrant } \\
\text { of abdomen }\end{array}$ & $\begin{array}{l}\text { Other quadrants } \\
\text { of abdomen }\end{array}$ & 207 & 63 & 188 & 426 \\
\hline $\begin{array}{l}\text { 4. Duration of pain: Duration } \\
\text { of pain at diagnosis }\end{array}$ & $\leq 12 \mathrm{~h}$ & $>12 \mathrm{~h}$ & 80 & 190 & 217 & 397 \\
\hline 5. Intensity of abdominal pain & $\begin{array}{l}\text { Subjectively moderate/ } \\
\text { intolerable pain }\end{array}$ & Weak pain & 179 & 349 & 91 & 265 \\
\hline $\begin{array}{l}\text { 6. Progression of pain } \\
\text { from onset to diagnosis }\end{array}$ & $\begin{array}{l}\text { Subjectively same or } \\
\text { worse pain }\end{array}$ & $\begin{array}{l}\text { Weaker pain than } \\
\text { at the onset }\end{array}$ & 190 & 72 & 375 & 239 \\
\hline 7. Type of pain & Subjectively steady pain & Colicky or intermittent pain & 190 & 80 & 313 & 301 \\
\hline 8. Aggravating factors & $\begin{array}{l}\text { Movement, coughing, } \\
\text { respiration, food or other }\end{array}$ & No aggravating factors & 244 & 26 & 410 & 204 \\
\hline 9. Relieving factors & No relieving factors & $\begin{array}{l}\text { Vomiting, lying still, } \\
\text { food, antacids or } \\
\text { no relieving factors }\end{array}$ & 52 & 218 & 233 & 381 \\
\hline 10. Previous similar pain & No & Yes & 229 & 35 & 397 & 210 \\
\hline 11. Vertigo & No & Yes & 270 & 0 & 588 & 23 \\
\hline 12. Nausea & Yes & No & 153 & 117 & 326 & 288 \\
\hline 13. Vomiting & Yes & No & 129 & 141 & 211 & 403 \\
\hline 14. Appetite & No appetite & Normal appetite & 219 & 51 & 407 & 207 \\
\hline 15. Previous indigestion & No & Yes & 240 & 30 & 504 & 108 \\
\hline 16. Jaundice & No & Yes & 269 & 1 & 613 & 3 \\
\hline 17. Bowels & Normal & $\begin{array}{l}\text { Constipation, diarrhea, } \\
\text { blood, mucus, white or } \\
\text { normal stools }\end{array}$ & 226 & 44 & 472 & 142 \\
\hline 18. Micturition & Normal & Abnormal & 263 & 7 & 581 & 33 \\
\hline 19. Drugs for abdominal pain & No & Yes & 268 & 2 & 589 & 25 \\
\hline 20. Previous abdominal surgery & No & Yes & 247 & 23 & 477 & 137 \\
\hline 21. Previous abdominal diseases & No & Yes & 249 & 21 & 516 & 98 \\
\hline 22. Use of alcohol & No & Yes & 268 & 2 & 581 & 33 \\
\hline
\end{tabular}

Table III. The clinical signs and tests of patients with acute appendicitis versus non-specific abdominal pain.

\begin{tabular}{|c|c|c|c|c|c|c|}
\hline Clinical signs and investigations & Positive endpoint & Negative endpoint & ТP & FN & FP & $\mathrm{TN}$ \\
\hline 1. Mood & Normal & Distressed or anxious & 233 & 37 & 537 & 77 \\
\hline 2. Colour & Normal & $\begin{array}{l}\text { Jaundiced, flushed, } \\
\text { pale or cyanosed }\end{array}$ & 245 & 25 & 556 & 58 \\
\hline 3. Abdominal movement & Normal & Poor/nil & 245 & 25 & 594 & 20 \\
\hline 4. Scar & No & Yes & 246 & 24 & 469 & 145 \\
\hline 5. Distension & No & Yes & 264 & 6 & 596 & 18 \\
\hline 6. Tenderness (OMGE) & $\begin{array}{l}\text { Right lower quadrant } \\
\text { of abdomen }\end{array}$ & $\begin{array}{l}\text { Other quadrants } \\
\text { of abdomen }\end{array}$ & 248 & 22 & 223 & 391 \\
\hline 7. Mass & No & Yes & 269 & 1 & 612 & 2 \\
\hline 8. Rebound & Yes & No & 247 & 23 & 180 & 434 \\
\hline 9. Guarding & Yes & No & 243 & 27 & 201 & 413 \\
\hline 10 . Rigidity & Yes & No & 171 & 99 & 11 & 602 \\
\hline 11. Murphy's positive & No & Yes & 259 & 11 & 601 & 13 \\
\hline 12. Bowel sounds & Normal & Abnormal & 236 & 34 & 571 & 43 \\
\hline 13. Renal tenderness & No & Yes & 200 & 70 & 496 & 118 \\
\hline 14. Rectal digital tenderness & Abnormal & Normal & 142 & 128 & 147 & 467 \\
\hline 15. Body temperature (Temp) & $>37.1^{\circ} \mathrm{C}$ & $\leq 37.1^{\circ} \mathrm{C}$ & 175 & 90 & 210 & 352 \\
\hline 16. Leucocyte count (LC) & $>10,000 / \mathrm{mm}^{3}$ & $\leq 10,000 / \mathrm{mm}^{3}$ & 190 & 57 & 132 & 361 \\
\hline 17. Urine & Normal & Haematuria or bacteriuria & 241 & 1 & 543 & 6 \\
\hline
\end{tabular}




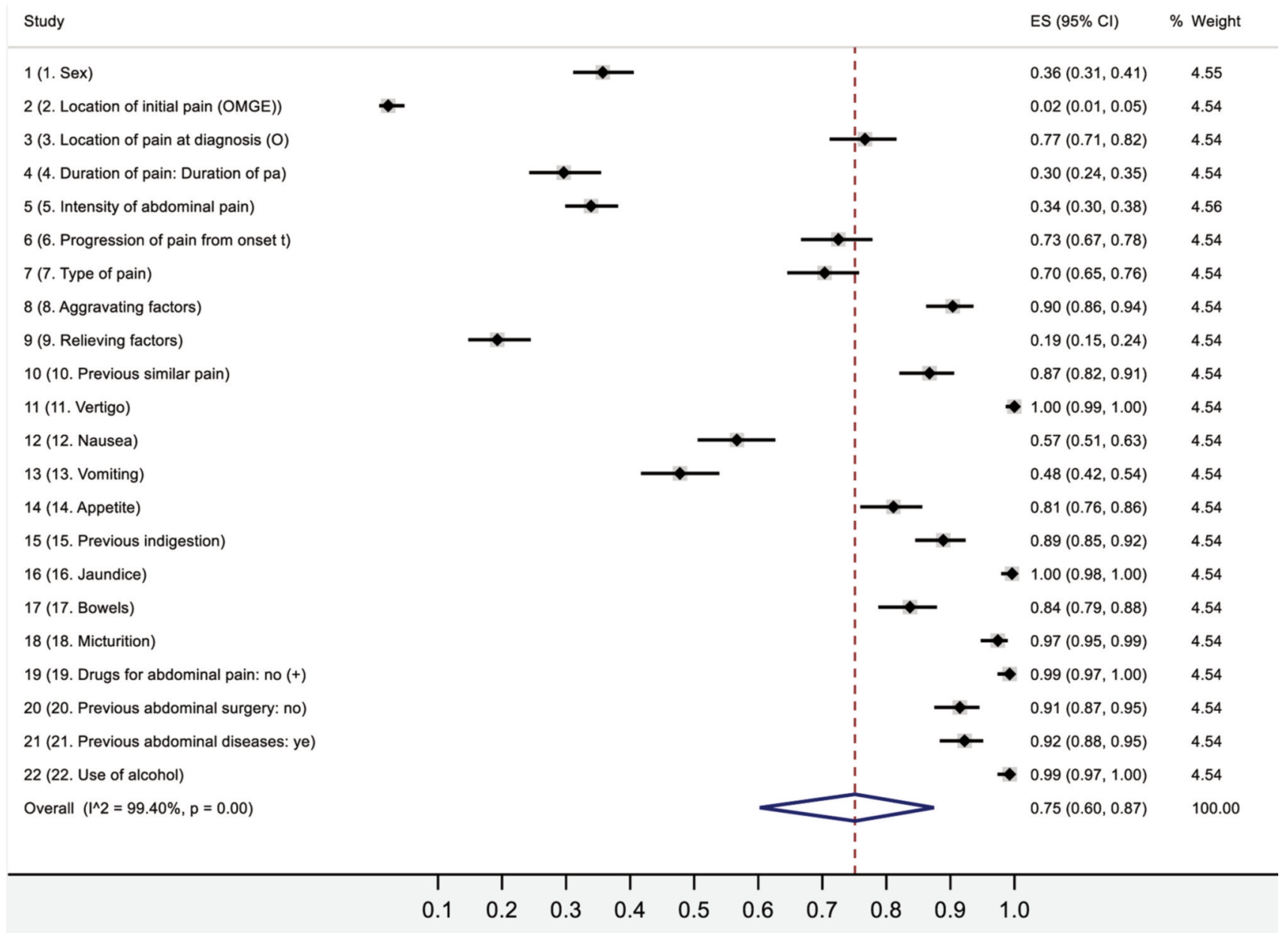

Figure 1. Pooled sensitivities of the clinical symptoms in acute appendicitis (random-effects model). ES: Estimated sensitivity; CI: confidence interval.

Table IV. Diagnostic score without leucocyte count $\left(D S_{L C-}\right)$ shown as six different combinations of symptoms, signs and test.

\begin{tabular}{|c|c|c|c|c|c|c|}
\hline Diagnostic score (DS) & Positive endpoint & Negative endpoint & $\mathrm{TP}$ & FN & FP & $\mathrm{TN}$ \\
\hline 1. Logistic model without leucocyte count DS I & Appendicitis & Non-specific abdominal pain & 221 & 49 & 31 & 582 \\
\hline 2. Logistic model without leucocyte count DS II & Appendicitis & Non-specific abdominal pain & 227 & 43 & 40 & 573 \\
\hline 3. Logistic model without leucocyte count DS III & Appendicitis & Non-specific abdominal pain & 198 & 72 & 20 & 593 \\
\hline 4. Logistic model without leucocyte count DS IV & Appendicitis & Non-specific abdominal pain & 198 & 72 & 20 & 593 \\
\hline 5. Logistic model without leucocyte count DS V & Appendicitis & Non-specific abdominal pain & 231 & 39 & 59 & 554 \\
\hline 6. Logistic model without leucocyte count DS VI & Appendicitis & Non-specific abdominal pain & 170 & 100 & 10 & 603 \\
\hline
\end{tabular}

Diagnostic score values from DS I to DS VI formulas refer to different combination of symptoms, signs and tests.

surgery (positive endpoint $=1$, negative endpoint $=0)+6.91$. The mean (SD) of $\mathrm{DS}_{\mathrm{LC}-}$ values for AA $(\mathrm{n}=270)$ were -2.06 (2.2) and $\mathrm{DS}_{\mathrm{LC}-}$ mean $(\mathrm{SD})$ values for $\mathrm{NSAP}(\mathrm{n}=613)$ were 3.38 (1.91). This $\mathrm{DS}_{\mathrm{LC}-}$ formula shows $\mathrm{Se}$ of $82 \%(95 \% \mathrm{CI}=77-86 \%)$ and $\mathrm{Sp}$ of $95 \%(95 \% \mathrm{CI}=93-97 \%)$, which is the best diagnostic performance level for DS without LC (Figures 5 and 6).
Diagnostic performance of the DS with leucocytes $\left(D S_{L C+}\right)$. The most powerful predictors were used to build up six different $\mathrm{DS}_{\mathrm{LC}+}$ formulas for AA diagnosis (Table $\mathrm{V}$ ). The pooled overall $\mathrm{Se}$ and $\mathrm{Sp}$ of these six $\mathrm{DS}_{\mathrm{LC}+}$ models for AA diagnosis were $79 \%(95 \% \mathrm{CI}=72-85 \%)$ and $95 \%(95 \% \mathrm{CI}=93-$ 97\%) (Figures 7 and 8). At the best diagnostic performance 


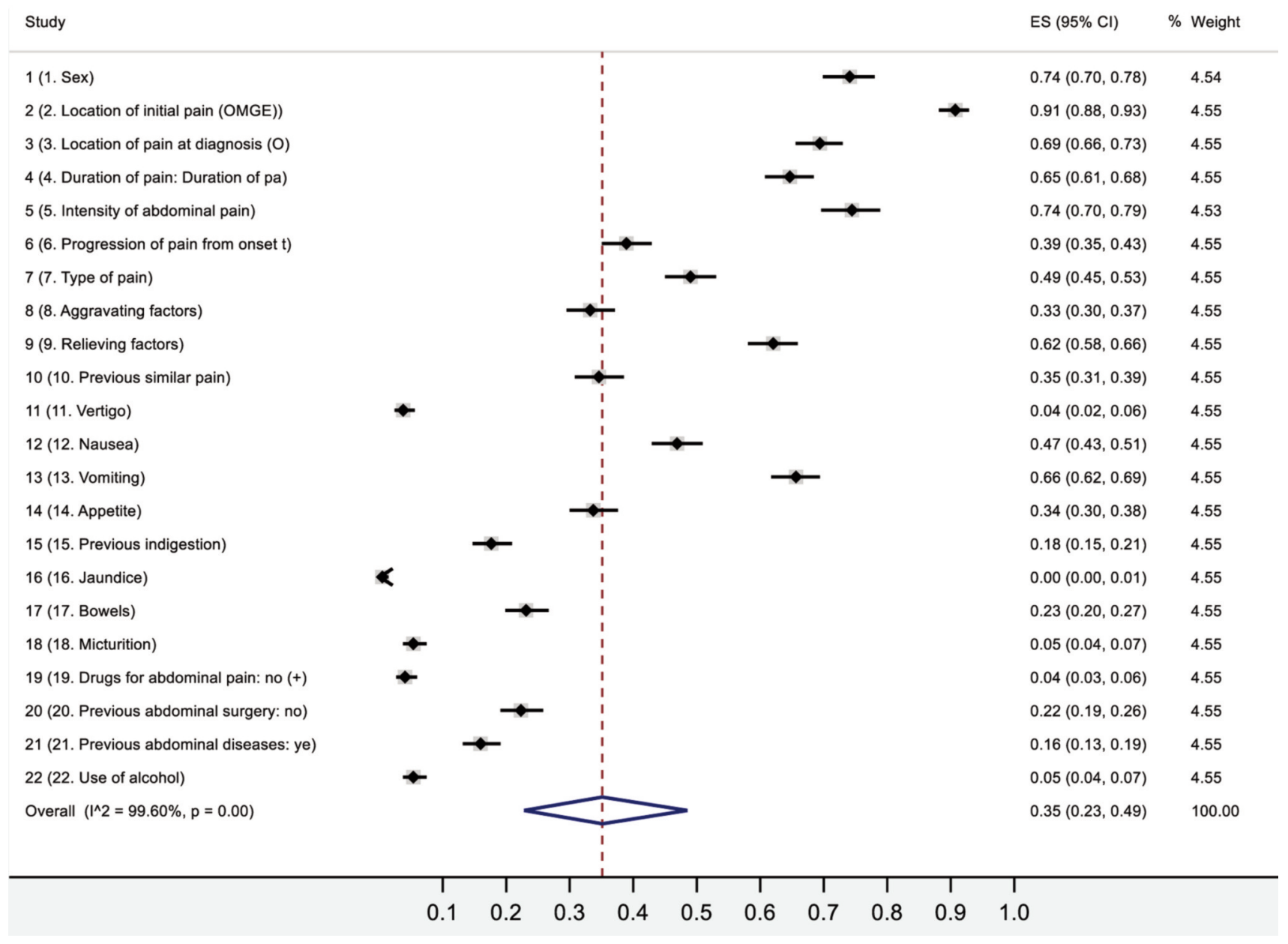

Figure 2. Pooled specificities of the clinical symptoms in acute appendicitis (random-effects model). ES: Estimated sensitivity; CI: confidence interval.

Table V. Diagnostic score with leucocyte count $\left(D S_{L C+}\right)$ shown as six different combinations of symptoms, signs and test.

\begin{tabular}{|c|c|c|c|c|c|c|}
\hline Diagnostic score (DS) & Positive endpoint & Negative endpoint & TP & FN & FP & $\mathrm{TN}$ \\
\hline 1. Logistic model with leucocyte count DS VII & Appendicitis & Non-specific abdominal pain & 202 & 45 & 23 & 469 \\
\hline 2. Logistic model with leucocyte count DS VIII & Appendicitis & Non-specific abdominal pain & 205 & 42 & 30 & 462 \\
\hline 3. Logistic model with leucocyte count DS IX & Appendicitis & Non-specific abdominal pain & 191 & 56 & 20 & 472 \\
\hline 4. Logistic model with leucocyte count DS X & Appendicitis & Non-specific abdominal pain & 200 & 47 & 26 & 466 \\
\hline 5. Logistic model with leucocyte count DS XI & Appendicitis & Non-specific abdominal pain & 214 & 33 & 50 & 442 \\
\hline 6. Logistic model with leucocyte count DS XII & Appendicitis & Non-specific abdominal pain & 155 & 92 & 10 & 482 \\
\hline
\end{tabular}

Diagnostic score values from DS VII to DS XII formulas refer to different combination of symptoms, signs and tests.

level for AA, the $\mathrm{DS}_{\mathrm{LC}+}$ (formula DS VII, Figures 7 and 8) showed $\mathrm{Se}$ of $82 \%(95 \% \mathrm{CI}=76-86 \%)$ and $\mathrm{Sp}$ of $95 \%$ (95\% CI $=93-97 \%)$, which is the best diagnostic performance level for DS with LC (Figures 7 and 8).

The Se of the best $\mathrm{DS}_{\mathrm{LC}-}$ and $\mathrm{DS}_{\mathrm{LC}+}$ formulas for detecting AA were equal: $82 \%(95 \% \mathrm{CI}=77-86 \%)$ and $82 \%(95 \% \mathrm{CI}=76-$
$86 \%$ ), respectively. The $\mathrm{Sp}$ of the best $\mathrm{DS}_{\mathrm{LC}-}$ and $\mathrm{DS}_{\mathrm{LC}+}$ formulas for detecting AA were identical: $95 \%$ (95\% CI=93$97 \%)$ and $95 \%(95 \% \mathrm{CI}=93-97 \%)$. The formula with $\mathrm{LC}$ $\left(\mathrm{DS}_{\mathrm{LC}+}\right)$ showing the highest diagnostic performance for AA in HSROC analysis (Figure 7) is the following: $\mathrm{DS}_{\mathrm{LC}+}=-$ $0.95 \times$ location of pain at diagnosis (positive endpoint $=1$, 


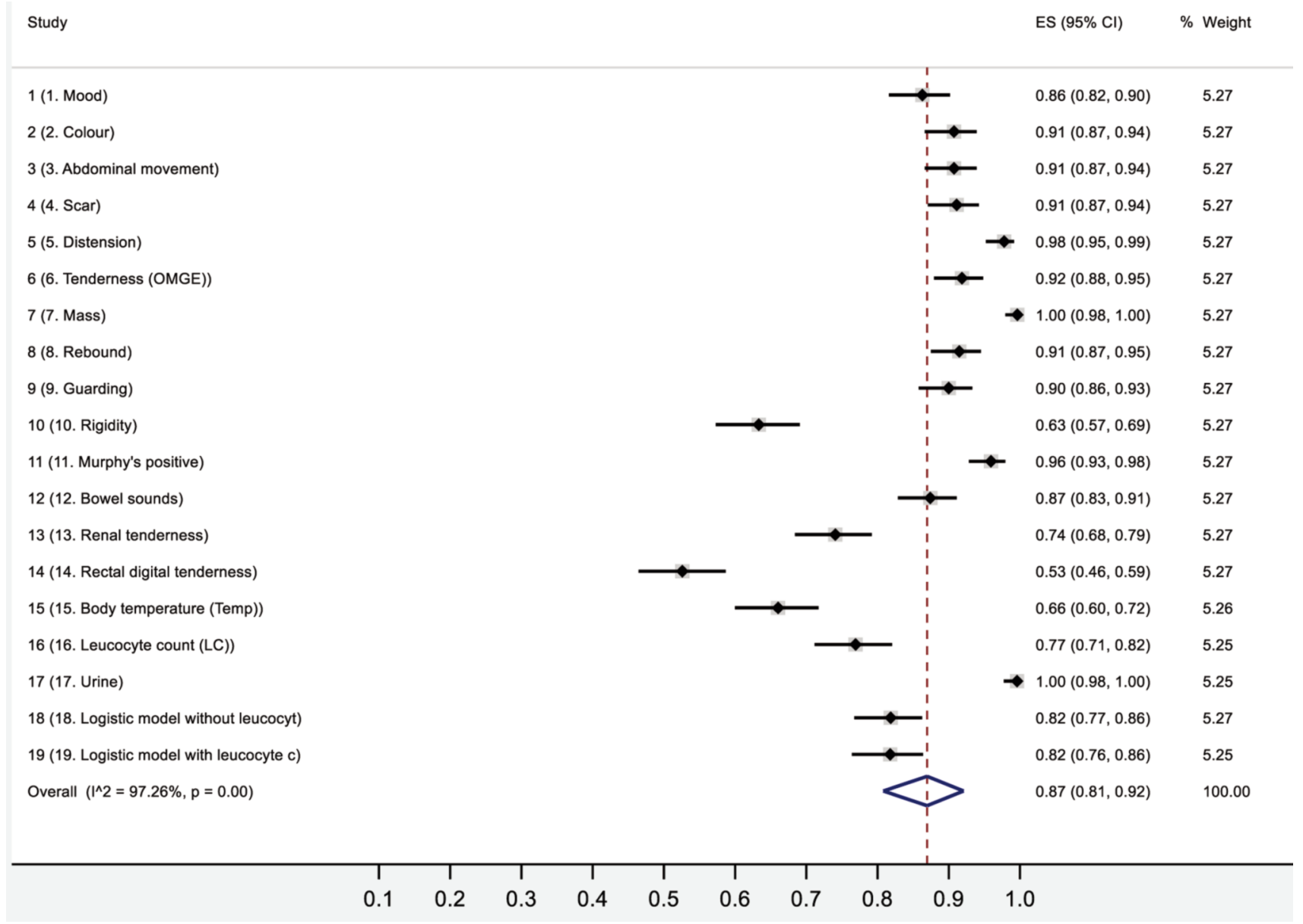

Figure 3. Pooled sensitivities of the clinical signs and tests in acute appendicitis (random-effects model). ES: Estimated sensitivity; CI: confidence interval.

negative endpoint $=0),-1.77 \times$ previous abdominal surgery (positive endpoint $=1$, negative endpoint $=0$ ), $-1.16 \times$ rebound (positive endpoint $=1$, negative endpoint $=0$ ), $-1.61 \times$ guarding (positive endpoint $=1$, negative endpoint $=0$ ), $-3.32 \times$ rigidity (positive endpoint $=1$, negative endpoint $=0$ ), $-0.97 \times$ tenderness (positive endpoint $=1$, negative endpoint $=0$ ) and $-2.2 \times \mathrm{LC}$ (positive endpoint $=1$, negative endpoint $=0)+7.035$. The mean (SD) of $\mathrm{DS}_{\mathrm{LC}+}$ values for AA $(\mathrm{n}=247)$ were -2.50 (2.27) and $\mathrm{DS}_{\mathrm{LC}+}$ mean $(\mathrm{SD})$ values for NSAP $(\mathrm{n}=492)$ were $3.38(2.12)$ (Figures 7 and 8).

HSROC analyses and empirical Bayes (EB) estimates. STATA (metandiplot algorithm) was used to draw the HSROC curves and empirical Bayes (EB) estimates to visualise the comparison of the pooled overall diagnostic performance of the diagnostic symptoms with the clinical signs and tests in AA diagnosis (Figures 9, 10, 11, and 12). HSROC curves and HSROC-EB estimates were also used to compare the pooled overall diagnostic performance of the different DS formulas in detecting AA (Figures 13, 14, 15, and 16). In the HSROC analysis, there was no statistically significant difference between the $\mathrm{DS}_{\mathrm{LC}_{-}}$and $\mathrm{DS}_{\mathrm{LC}+}$ formulas, with $\mathrm{AUC}=0.860 \quad(95 \% \mathrm{CI}=0.85-0.86) \quad$ and $\mathrm{AUC}=0.870 \quad(95 \% \mathrm{CI}=0.86-0.88)$, respectively $(p=0.799$, ROC comparison test).

\section{Discussion}

In this analysis, we focused on the diagnostic performance of the patients' symptoms/signs and DS in a clinical setting of patients with acute abdominal pain. The present study compared all predictive factors for AA diagnosis including 22 clinical symptoms and history variables with 14 diagnostic tests or signs. Sensitivity was defined as the proportion of AA positive patients among those who were diagnosed with the outcome of interest. Specificity referred to the number of participants with negative AA test results divided by the number of participants without AA.

Although there is a general impression that $\mathrm{DS}_{\mathrm{LC}+}$ performs better than $\mathrm{DS}_{\mathrm{LC}-}$, limited data on the performance 


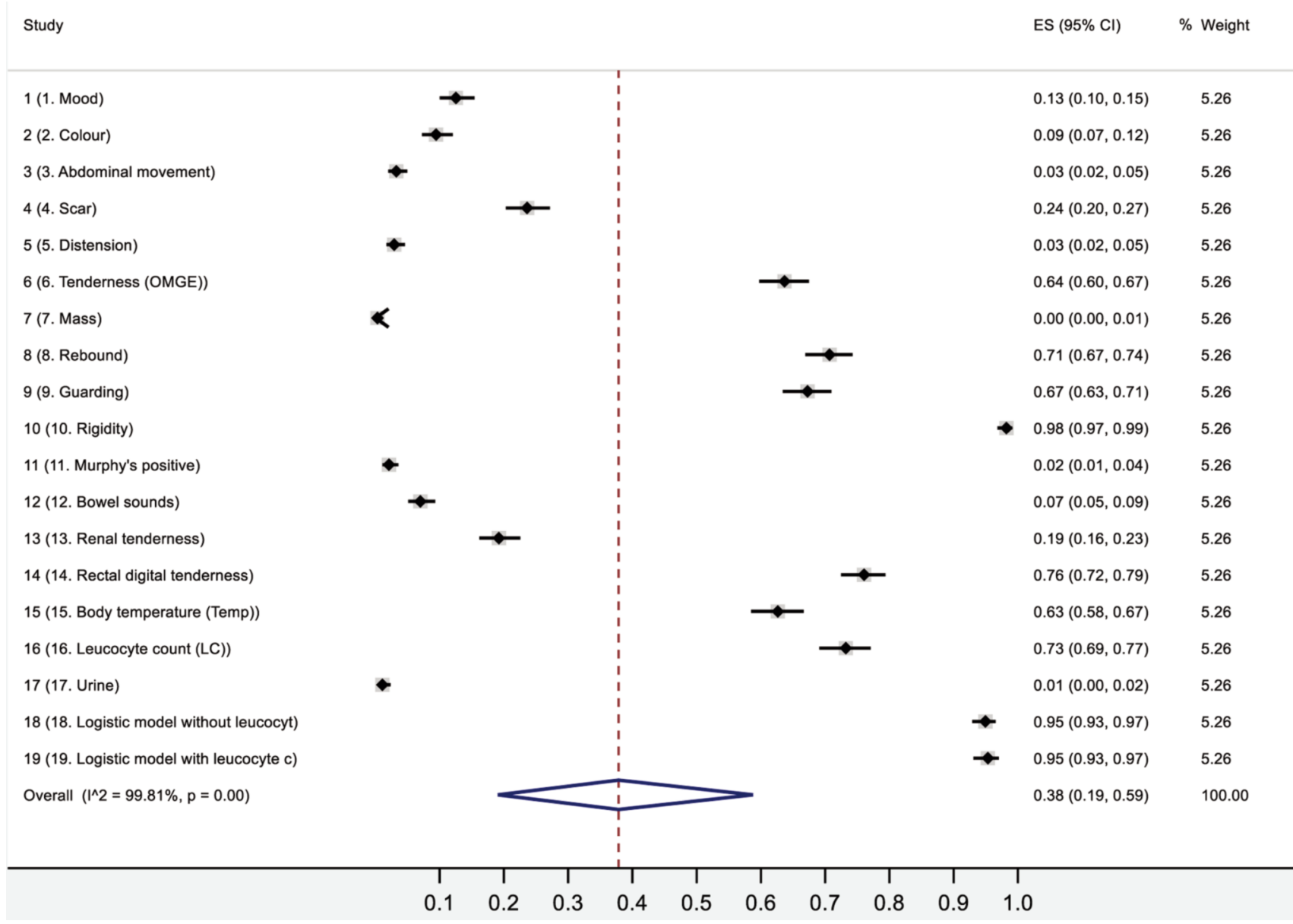

Figure 4. Pooled sensitivities of the clinical signs and tests in acute appendicitis (random-effects model). ES: Estimated sensitivity; CI: confidence interval.

of DS makes it difficult to decide which DS test to choose in the clinical diagnosis of AA to keep both negative appendectomy rate low (FP rate) and perforated appendix rate ( $\mathrm{FN}$ rate) at a minimum. To improve the diagnostic performance in AA, such inflammatory biomarkers as LC and C-reactive protein (CRP) have been included in the DS models as in Alvarado score (6). We feel that LC is more sensitive in early AA than CRP, which is related to the severity of the AA and is a possible biomarker of AA perforation.

Alvarado's DS is based on retrospective data of 305 patients with AAP and included 8 predictive factors for AA, each given a value of 1 point or 2 points based on the diagnostic weight for AA. One point was given for shifting of pain to the right lower quadrant (RLQ), anorexia, nausea or vomiting, rebound, body temperature $>37.3^{\circ} \mathrm{C}$ and LC left shift. Two points were given for tenderness at RLQ and LC $>10,000 / \mu \mathrm{l}$. Alvarado's recommendations for management of AA patients are based on the sum of the points of these eight variables. Alvarado score between 7 and 8 suggests that
"AA probable" and the score between 9 and 10 denotes "AA very probable". In a meta-analysis, Ohle et al. (11) estimated that Alvarado score has $82 \%$ Se and $81 \% \mathrm{Sp}$ at the score 7 cut-off level.

We have studied AAP in connection with the survey of OMGE (1) and investigated the diagnostic performance of history-taking, clinical signs and tests and computer-based decision in confirming AA (2). In Finland, a total of 1,333 patients presenting with AAP were included in the OMGE study (1) and 25 clinical history variables, 13 clinical signs and 3 tests were evaluated in multivariate analyses to find the optimal combinations of independent predictors of AA. The most important predictors of AA were tenderness, rigidity, rebound, $\mathrm{LC}$, location of pain and duration of pain. In practice, the use of DS is relatively simple as shown by the following; "A patient is admitted to the emergency room with abdominal pain of $\leq 48 \mathrm{~h}$ duration ( 2 points $\times 2,13$ ); at onset the pain was localized in the upper abdomen, but has shifted to RLQ (2 points $\times 3.51)$; clinical examination showed RLQ tenderness (2 points $\times 11.4$ ) and rigidity (2 


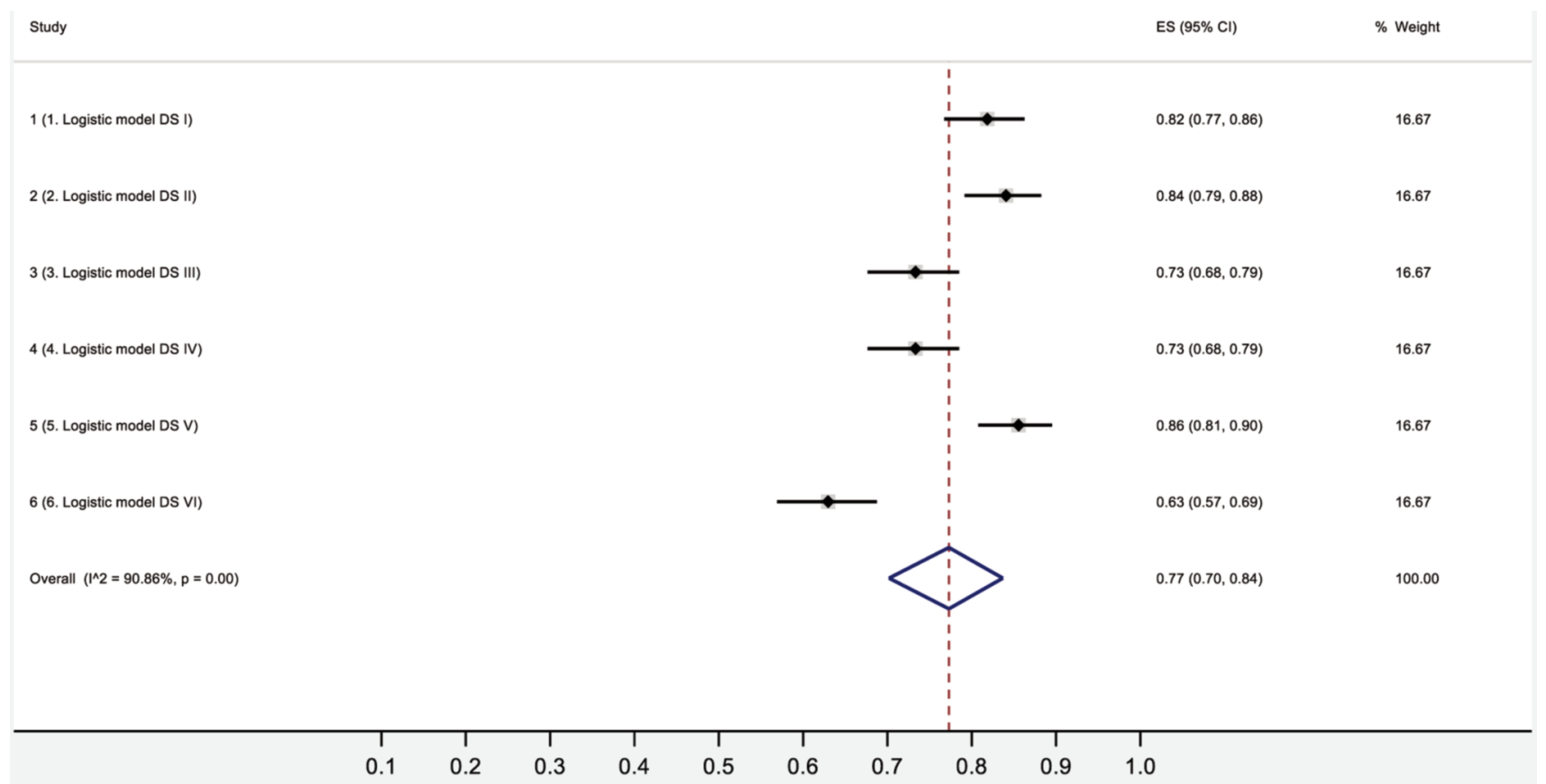

Figure 5. Sensitivities of diagnostic scores without leucocyte count (DSLC-) shown as six different combination of symptoms, signs and test.

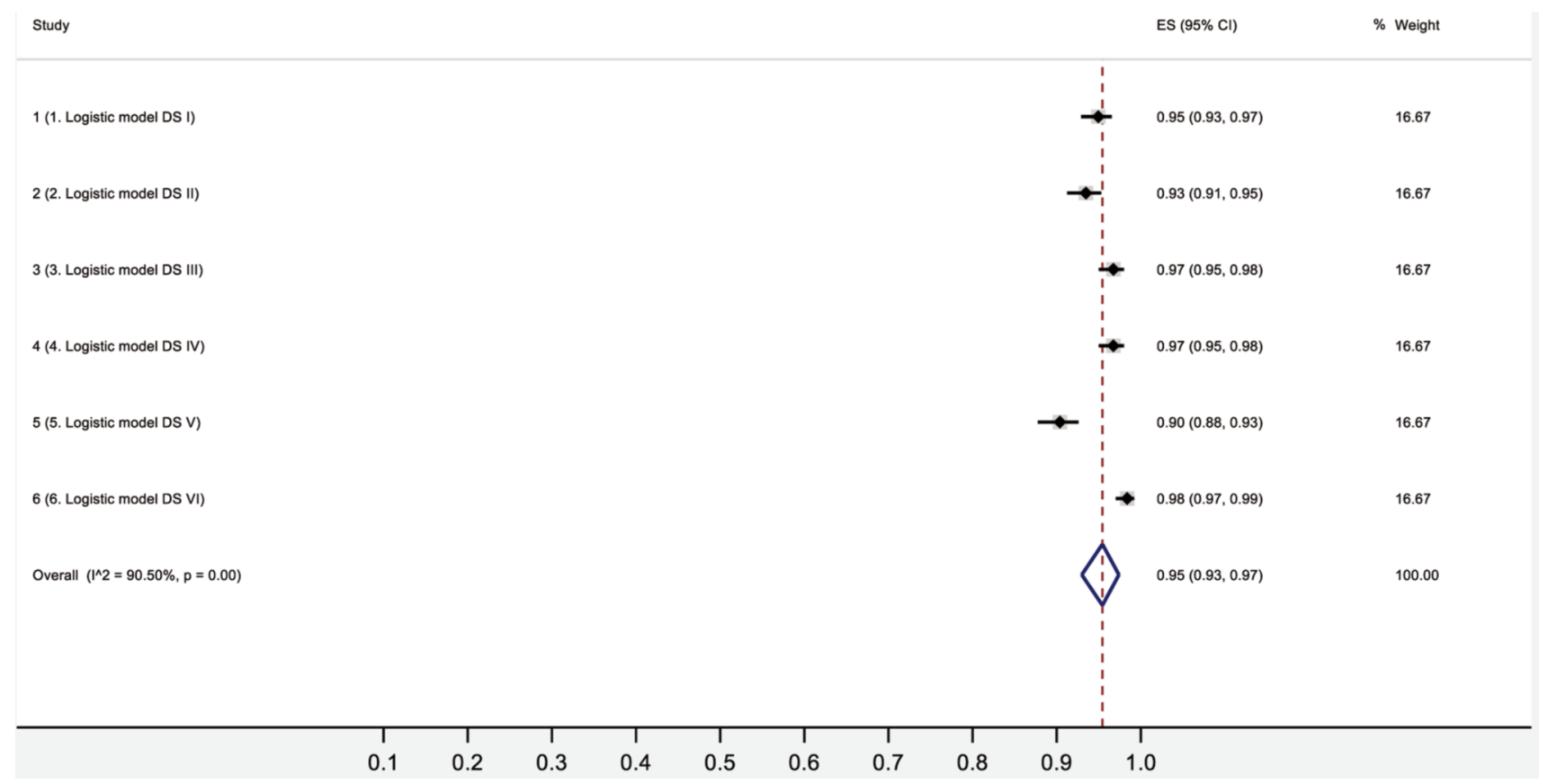

Figure 6. Specificities of diagnostic scores without leucocyte count $\left(D S_{L C-}\right)$ shown as six different combination of symptoms, signs and test.

points $\times 6.62)$, and the rebound tests were positive $(2$ points $\times 5.58)$; LC test showed positive value $(\geq 10,000 / \mu 1$, 5.87). In this example, the total score is 67 points and diagnosis is AA. Our original cut-off level for AA was 55 points (2). Sitter et al. (8) tested our DS in a prospective trial including 2,359 patients with AAP. After careful analysis they suggested a higher cut-off value of 57 points, which gives $91 \%$ AUC for the AA endpoint. 


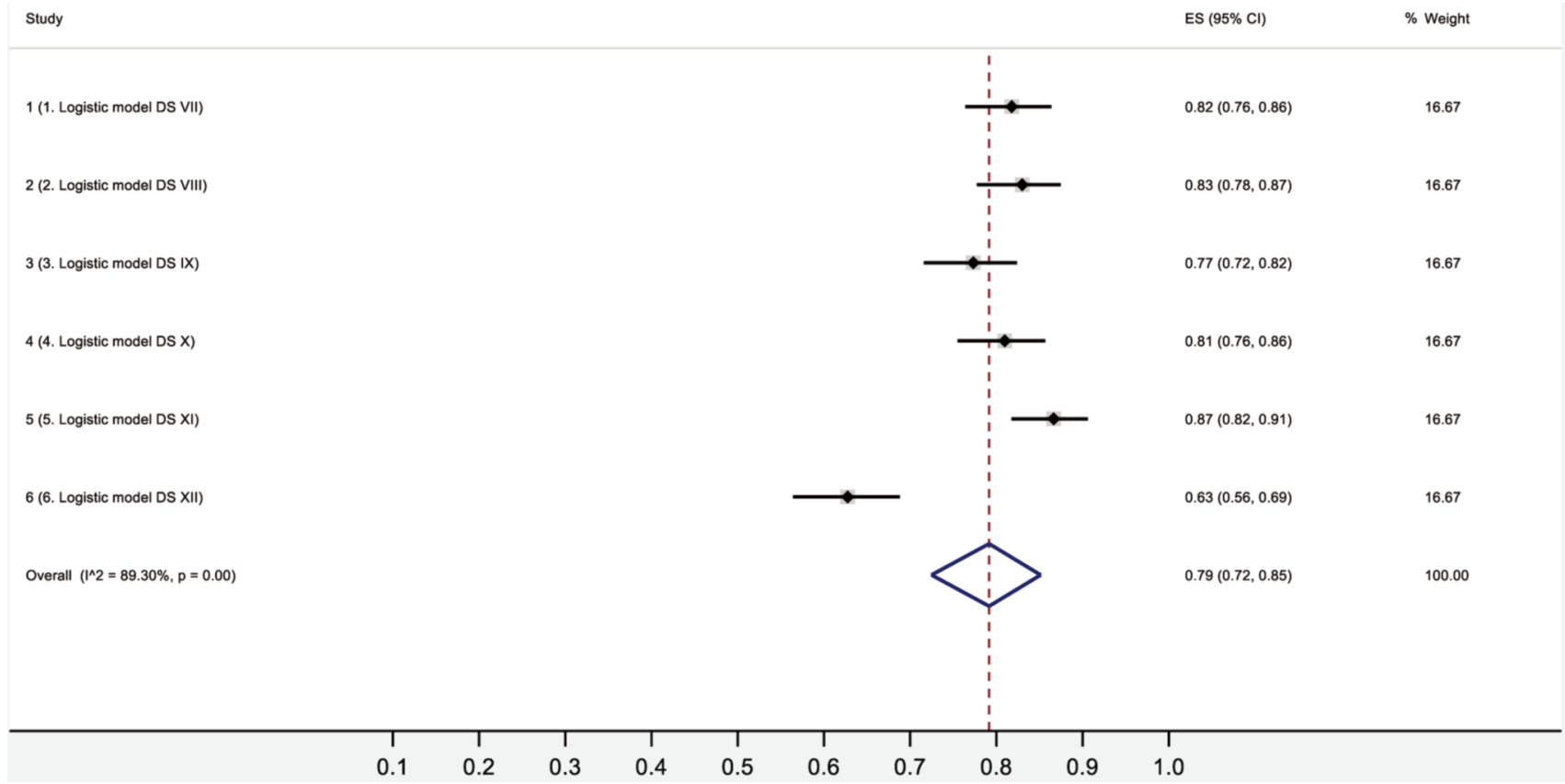

Figure 7. Sensitivities of diagnostic scores with leucocyte count $\left(D S_{L C+}\right)$ shown as six different combinations of symptoms, signs and test.

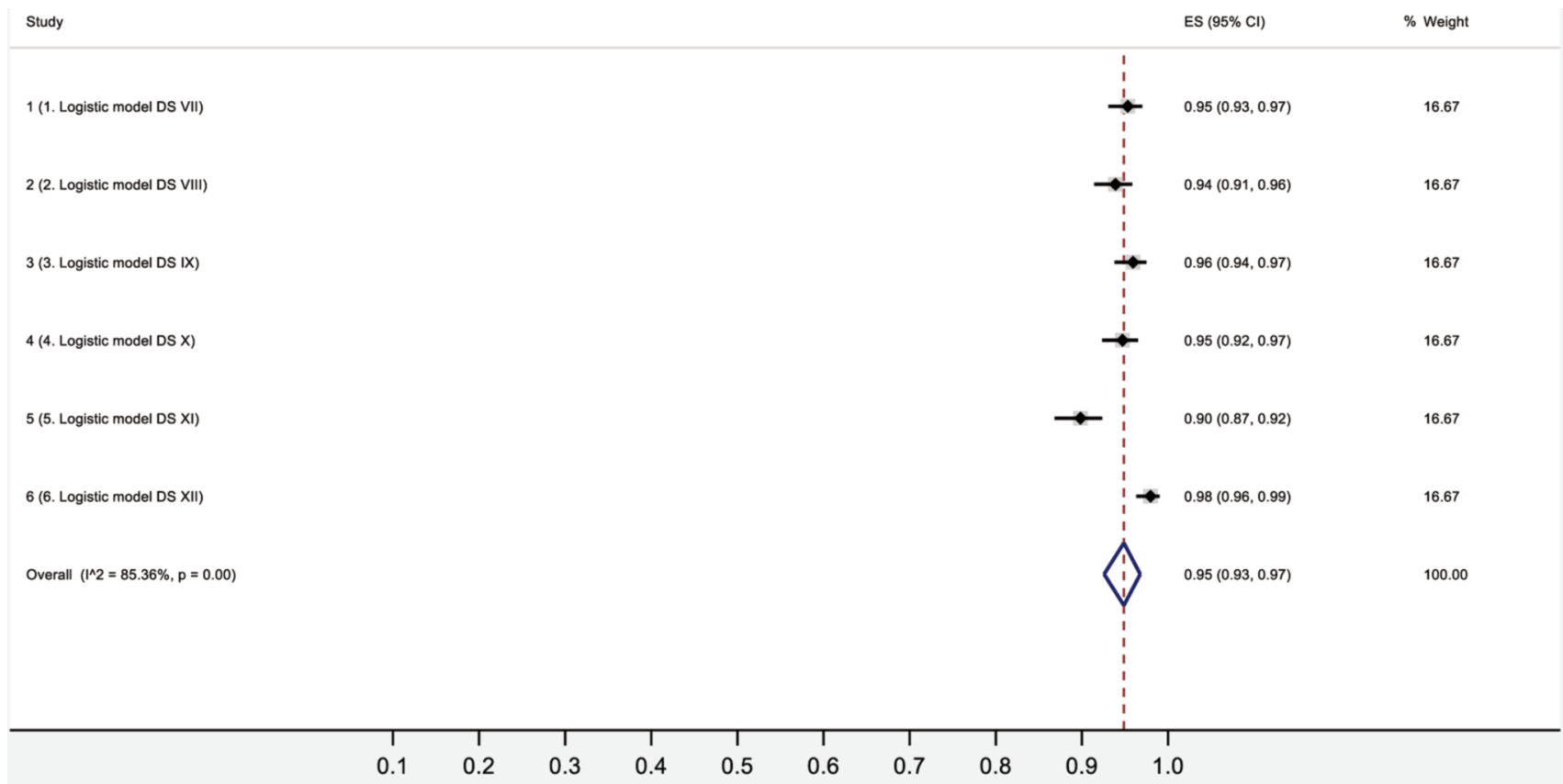

Figure 8. Specificities of diagnostic scores with leucocyte count $\left(D S_{L C+}\right)$ shown as six different combinations of symptoms, signs and tests.

Ohmann et al. (7) formulated a DS including 8 factors; Age $<50$ years, shifting of pain to RLQ, type of pain (steady), micturition (normal), tenderness, rebound, rigidity, $\mathrm{LC} \geq 10,000 / \mu 1$. However, when tested in a clinical setting, the Ohmann score did not significantly improve the clinical performance of AA diagnosis (7).

Tzanakis et al. (10) introduced DS for AA diagnosis using a combination of clinical tests for tenderness and rebound in 


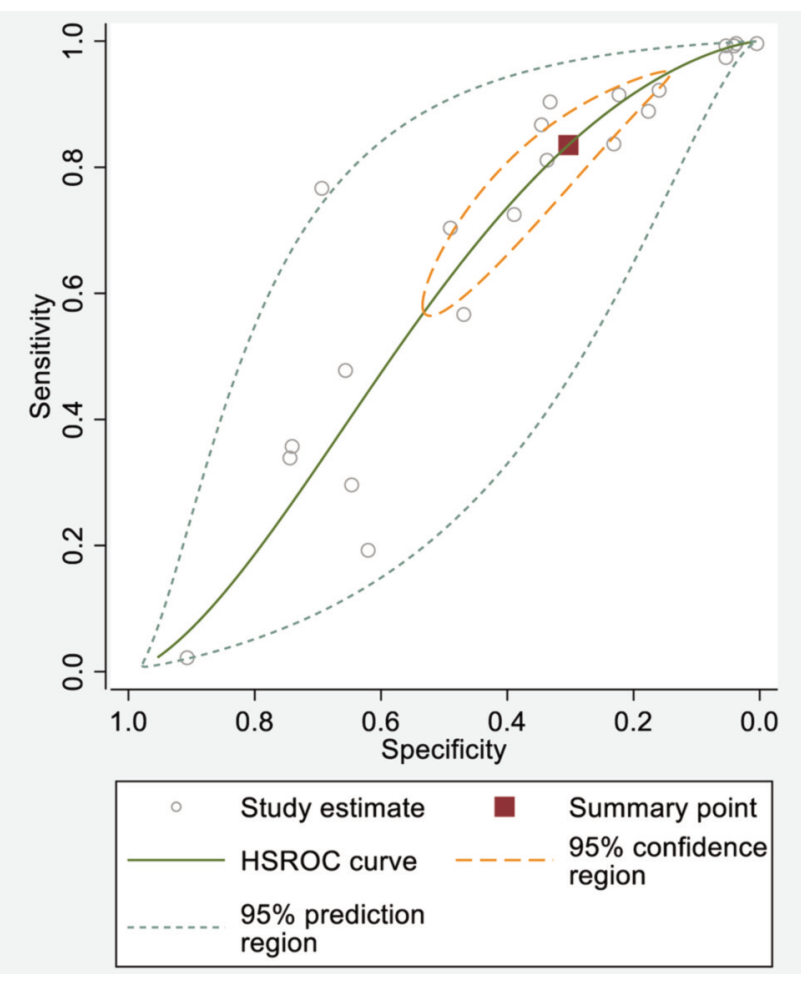

Figure 9. Hierarchical summary receiver operating characteristic (HSROC) curve of the clinical symptoms.

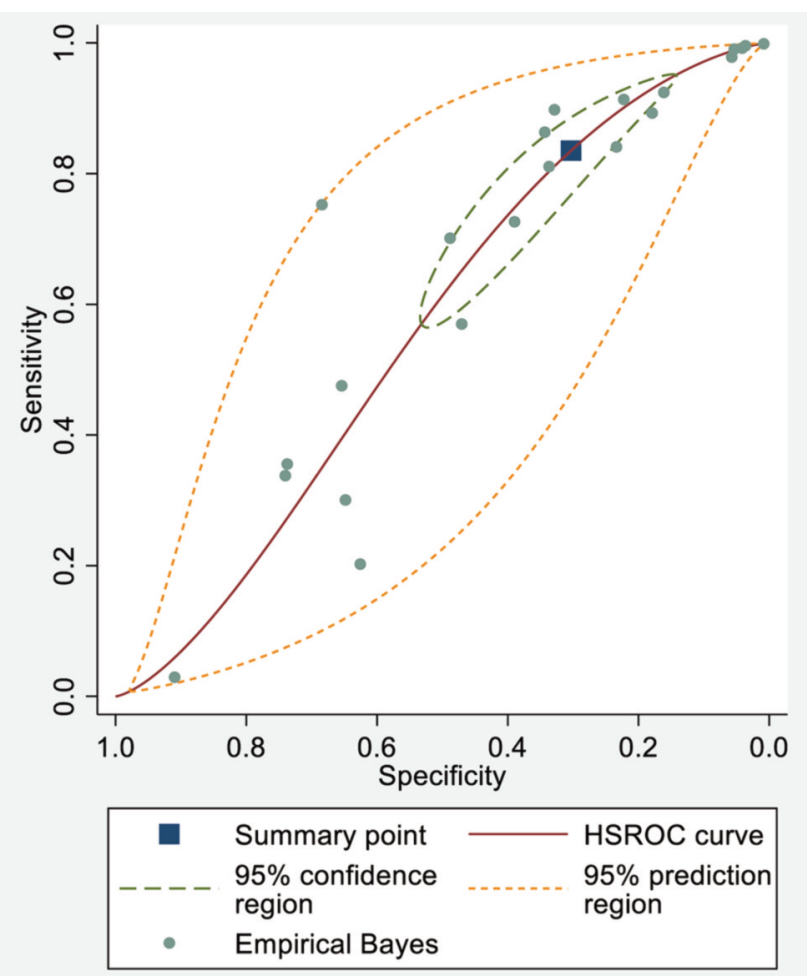

Figure 10. Hierarchical summary receiver operating characteristic (HSROC) and Empirical Bayes curves of the clinical symptoms.

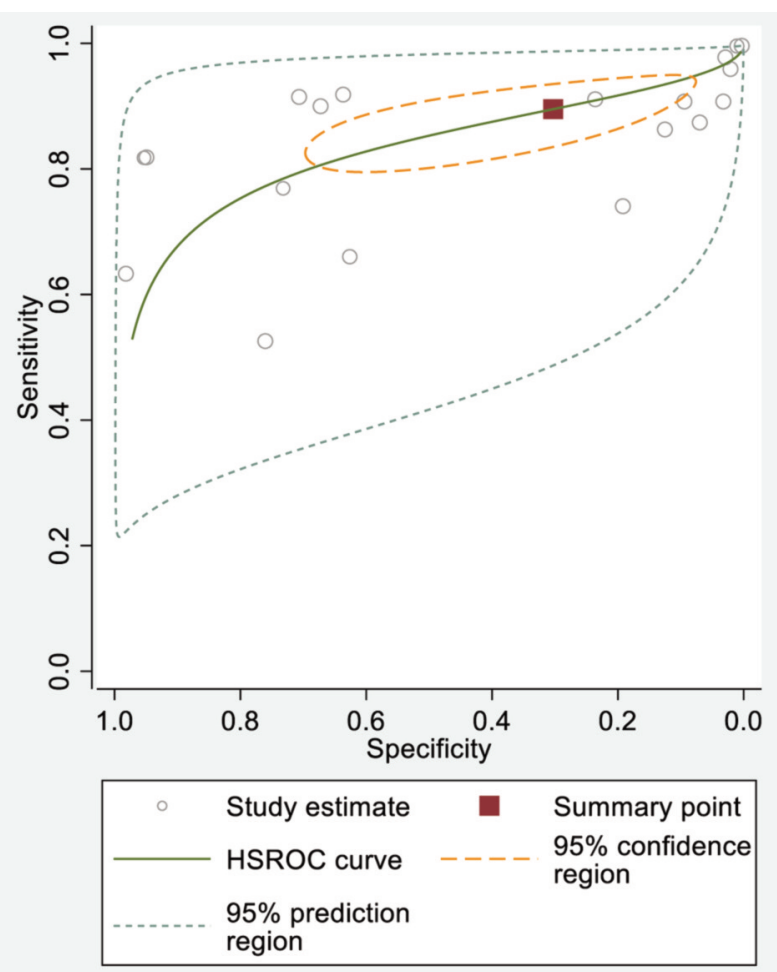

Figure 11. Hierarchical summary receiver operating characteristic (HSROC) curve of the clinical signs and tests.

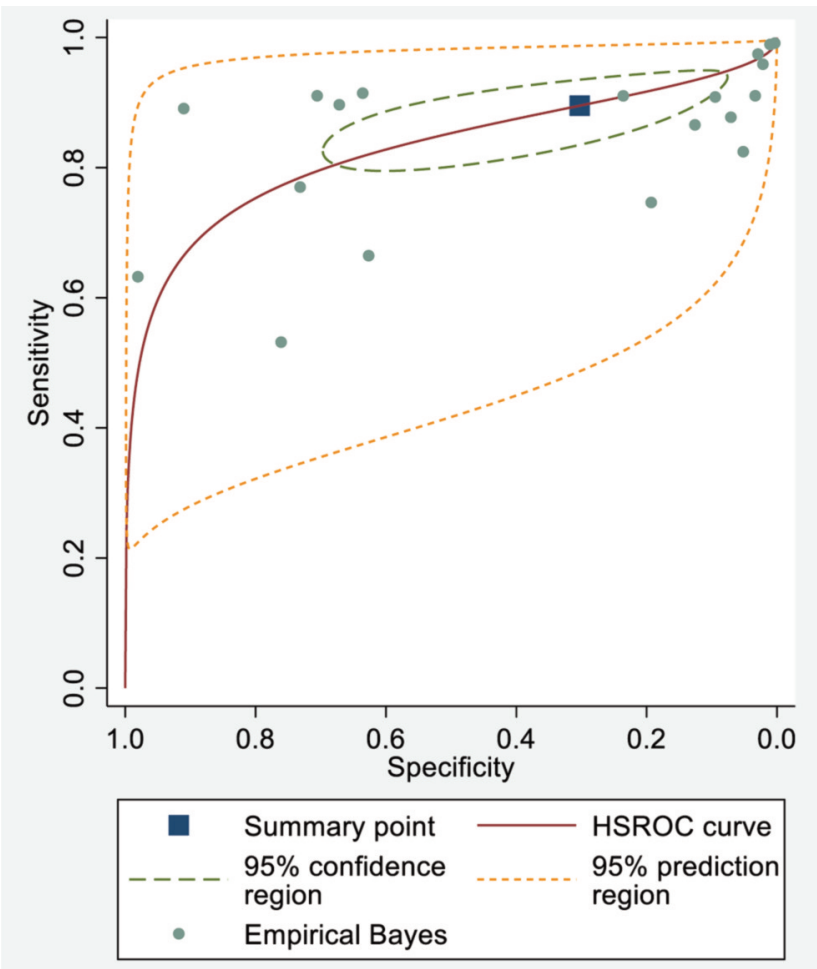

Figure 12. Hierarchical summary receiver operating characteristic (HSROC) and Empirical Bayes curves of the clinical signs and tests. 


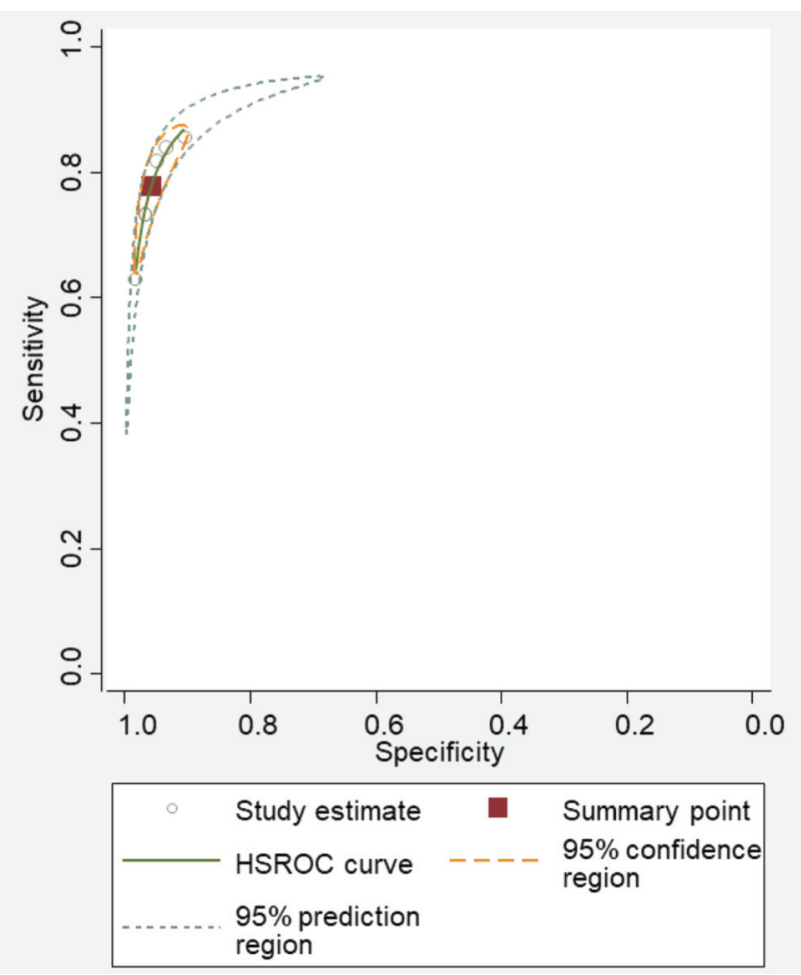

Figure 13. Hierarchical summary receiver operating characteristic (HSROC) curve of the six $D S_{L C-}$ tests.

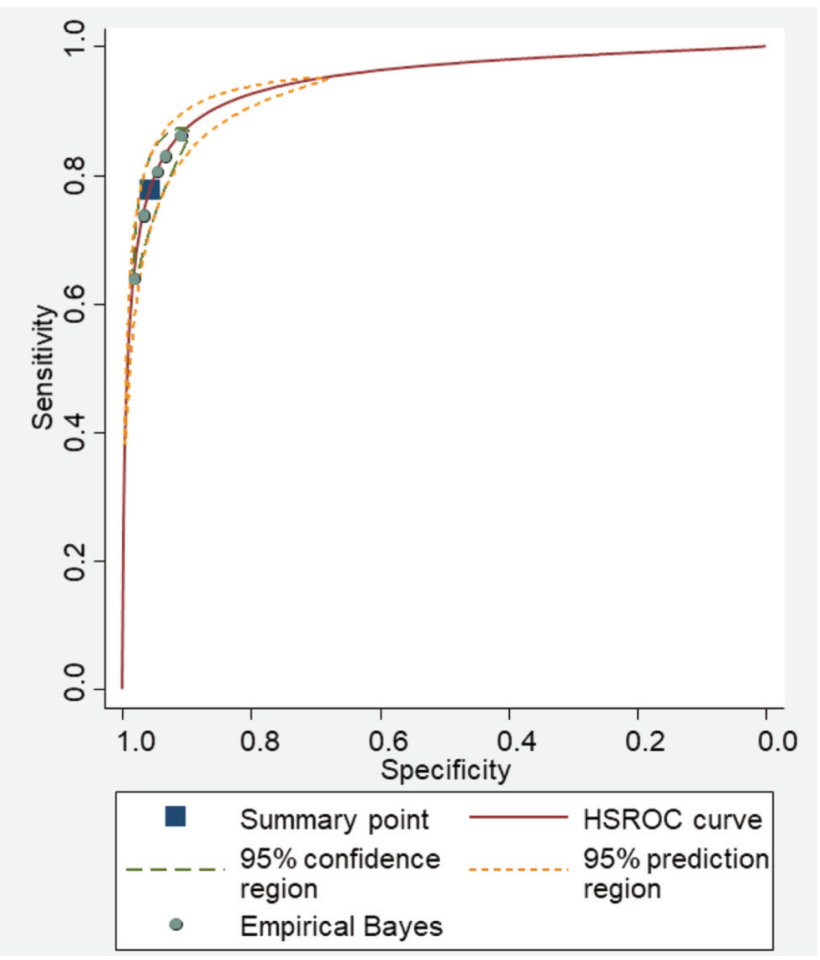

Figure 14. HSROC-Empirical Bayes Figure 5. Hierarchical summary receiver operating characteristic (HSROC) and Empirical Bayes curves of the six $D S_{L C-}$ tests.

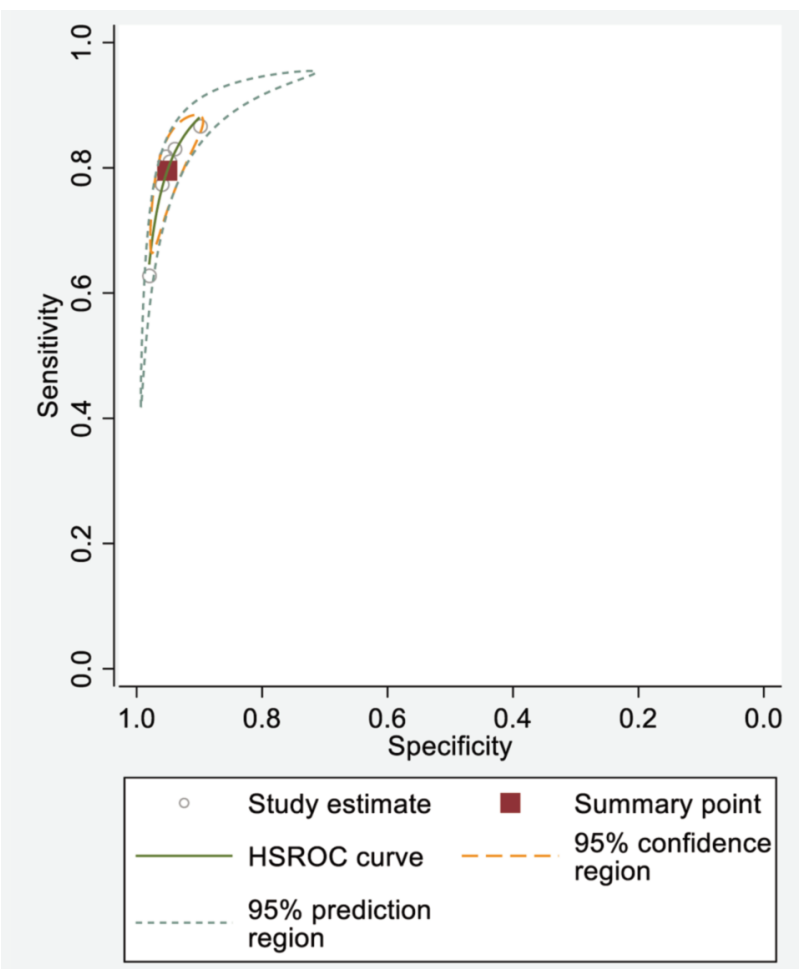

Figure 15. Hierarchical summary receiver operating characteristic (HSROC) curve of the six $D S_{L C+}$ tests.

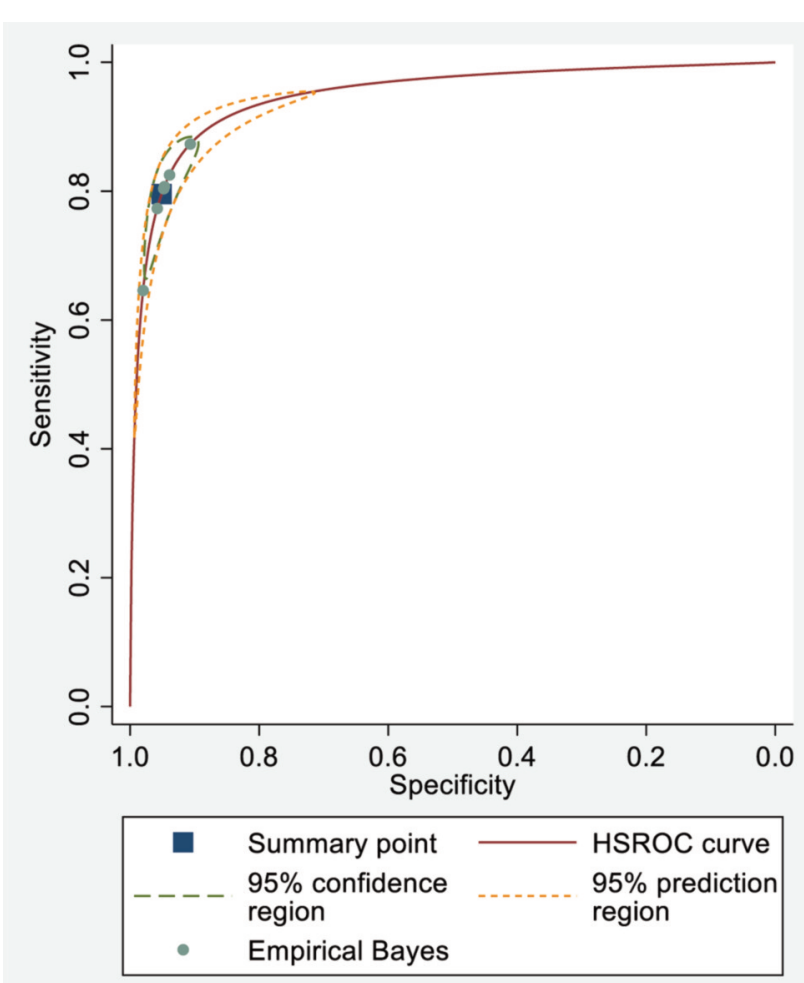

Figure 16. Hierarchical summary receiver operating characteristic (HSROC) and Empirical Bayes curves of the six $D S_{L C+}$ tests. 
combination with abdominal ultrasound examination (US) and LC (cut-off $>12,000 / \mu \mathrm{l}$ ). When tested in a clinical setting, their DS reached $90 \%$ AUC for the AA endpoint. Although US is less expensive than other imaging methods, its diagnostic performance still remains questionable, especially in borderline US findings and in problems to visualize retrocaecal appendix (12). In a prospective multicenter trial of 2,280 patients with AAP, Franke et al. (12) reported no correlation between the diagnostic performance of US and a clinician, and the negative appendectomy or perforation rate, thus showing no clear benefit of US in AA diagnosis. In another study, Lee et al. (13) found US to even delay appendectomy in a cohort of 766 patients.

In our study, the LC test showed Se of $82 \%(95 \% \mathrm{CI}=76-$ $86 \%)$ and $\mathrm{Sp}$ of $95 \%(95 \% \mathrm{CI}=93-97 \%)$, suggesting that the routine determination of the total number of leucocytes and their relative ratio could help in AA diagnosis. However, the delay of appendectomy should be kept in mind, especially when the LC is not fully necessary to support the AA diagnosis. To find the optimal combination of symptoms, signs and tests in the DS formula, we compared the $\mathrm{DS}_{\mathrm{LC}-}$ and $\mathrm{DS}_{\mathrm{LC}+}$ models at six different combinations of predictors. No significant difference in performance between $\mathrm{DS}_{\mathrm{LC}-}$ and $\mathrm{DS}_{\mathrm{LC}+}$ formulas were detected. In the AA endpoint, $\mathrm{DS}_{\mathrm{LC}-}$ and $\mathrm{DS}_{\mathrm{LC}+}$ formulas showed almost equal AUC values in HSROC analysis ( 0.86 versus $0.87, p=0.799)$.

The new diagnostic strategies of AA, beside the DS formulas and US may include interleukin 6 (IL-6), which is an early marker of inflammation. IL- 6 blood levels were shown to increase even 3-fold from the IL-6 reference levels in $90 \%$ of the patients with perforated appendicitis $(14,15)$. Anielski et al. (15) found significantly higher IL-6 serum levels in patients with gangrenous perforated AA, suggesting that IL-6 test could be useful in assessing the risk of complications during the course of AA. Although, the IL-6 results are promising, the current enzyme-linked immunosorbent assay (ELISA) precludes its use as a pointof-care (POC) test in AA so far $(16,17)$.

In conclusion, the DS test could assist the clinician in differentiating AA from NSAP and other causes of acute abdominal pain. Importantly, LC does not improve the diagnostic performance of a DS in AA.

\section{Conflicts of Interest}

The Authors report no conflicts of interest or financial ties in relation to this study. The Authors alone are responsible for the content and writing of this article.

\section{Authors' Contributions}

All Authors have met all of the following four criteria: 1 . Substantial contributions to the conception or design of the work or the acquisition, analysis, or interpretation of data for the work, 2.
Drafting the work or revising it critically for important intellectual content, 3. Final approval of the version to be published, 4 . Agreement to be accountable for all aspects of the work in ensuring that questions related to the accuracy or integrity of any part of the work are appropriately investigated and resolved.

\section{Acknowledgements}

The study was funded by the Päivikki ja Sakari Sohlberg Foundation.

\section{References}

1 De Dombal FT: The OMGE acute abdominal pain survey. Progress report 1986. Scand J Gastroenterol 23: 35-42, 1988. PMID: 3043646.

2 Eskelinen M, Ikonen J and Lipponen P: Clinical diagnosis of acute appendicitis. A prospective study of patients with acute abdominal pain. Theor Surg 7: 81-85, 1992.

3 Eskelinen $\mathrm{M}$ and Lipponen P: Usefulness of history-taking in non-specific abdominal pain: A prospective study of 1333 patients with acute abdominal pain in Finland. In Vivo 26: 335 339, 2012. PMID: 22351680

4 Eskelinen M, Ikonen J and Lipponen P: Contributions of historytaking, physical examination, and computer assistance to diagnosis of acute small-bowel obstruction. A prospective study of 1333 patients with acute abdominal pain. Scand J Gastroenterol 29: 715721, 1994. PMID: 7973431. DOI: 10.3109/00365529409092499

5 Eskelinen M, Ikonen J and Lipponen P: Usefulness of historytaking, physical examination and diagnostic scoring in acute renal colic. Eur Urol 34: 467-473, 1998. PMID: 9831787. DOI: $10.1159 / 000019785$

6 Alvarado A: A practical score for the early diagnosis of acute appendicitis. Ann Emerg Med 15: 557-564, 1986. PMID: 3963537. DOI: 10.1016/s0196-0644(86)80993-3

7 Ohmann C, Franke C and Yang Q: Clinical benefit of a diagnostic score for appendicitis: results of a prospective interventional study. German Study Group of Acute Abdominal Pain. Arch Surg 134: 993-996, 1999. PMID: 10487595. DOI: 10.1001/archsurg.134.9.993

8 Sitter H, Hoffmann S, Hassan I and Zielke A: Diagnostic score in appendicitis. Validation of a diagnostic score (Eskelinen Score) in patients in whom acute appendicitis is suspected. Langenbecks Arch Surg 389: 213-218, 2004. PMID: 14624293. DOI: $10.1007 / \mathrm{s} 00423-003-0436-9$

9 Lintula H, Pesonen E, Kokki H, Vanamo K and Eskelinen M: A diagnostic score for children with suspected appendicitis. Langenbecks Arch Surg 390: 164-170, 2005. PMID: 15723233. DOI: $10.1007 /$ s00423-005-0545-8

10 Tzanakis NE, Efstathiou SP, Danulidis K, Rallis GE, Tsioulos DI, Chatzivasiliou, Peros G and Nikiteas NI: A new approach to accurate diagnosis of acute appendicitis. World J Surg 29: 11511156, 2005. PMID: 16088420. DOI: 10.1007/s00268-005-7853-6

11 Ohle R, O'Reilly F, O'Brien KK, Fahey T and Dimitrov BD: The Alvarado Score for predicting acute appendicitis: A systematic review. BMC Med 9: 139, 2011. PMID: 22204638. DOI: 10.1186/1741-7015-9-139

12 Franke C, Böhner H, Yang Q, Ohmann C and Röher HD: Ultrasonography for diagnosis of acute appendicitis: results of a prospective multicenter trial. Acute Abdominal Pain Study 
Group. World J Surg 23: 141-146, 1999. PMID: 9880422. DOI: $10.1007 / \mathrm{p} 100013165$

13 Lee SL, Walsh AJ and Ho HS: Computed tomography and ultrasonography do not improve and may delay the diagnosis and treatment of acute appendicitis. Arch Surg 136: 556-562, 2001. PMID: 11343547. DOI: 10.1001/archsurg.136.5.556

14 Almagor M, Mintz A, Sibirsky O and Durst A: Preoperative and postoperative levels of interleukin-6 in patients with acute appendicitis: comparison between open and laparoscopic appendectomy. Surg Endosc 19: 331-333, 2005. PMID: 15645323. DOI: 10.1007/s00464-003-9311-6

15 Anielski R, Kuśnierz-Cabala B and Szafraniec K: An evaluation of the utility of additional tests in the preoperative diagnostics of acute appendicitis. Langenbecks Arch Surg 395: 1061-1068, 2010. PMID: 19924436. DOI: 10.1007/s00423-009-0565-x

16 Aspinen S, Kinnunen M, Harju J, Juvonen P, Selander T, Holopainen A, Kokki H, Pulkki $\mathrm{K}$ and Eskelinen $\mathrm{M}$ : Inflammatory response to surgical trauma in patients with minilaparotomy cholecystectomy versus laparoscopic cholecystectomy: a randomised multicentre study. Scand J Gastroenterol 51: 739-744, 2016. PMID: 26758677. DOI: 10.3109/00365521.2015.1129436

17 Purdy M, Kokki M, Anttila M, Aspinen S, Juvonen P, Korhonen $\mathrm{R}$, Selander T, Kokki H and Eskelinen M: Does the rectus sheath block analgesia reduce the inflammatory response biomarkers' IL-1 ra, IL-6, IL-8, IL-10 and IL-1 $\beta$ concentrations following surgery? A randomized clinical trial of patients with cancer and benign disease. Anticancer Res 36: 3005-3011, 2016. PMID: 27272818 .

Received July 17, 2020

Revised July 30, 2020

Accepted August 3, 2020 